\title{
Morfologi dan Anatomi Chrysanthemum morifolium Ramat. var. puspita nusantara dan var. tirta ayuni serta Chrysanthemum indicum L.var. mustika kaniya
}

\author{
Isvana Dalaila1, Kusrinah², Lianah² \\ 1 Jurusan Pendidikan Biologi, Fakultas Sains dan Teknologi, UIN Walisongo Semarang \\ ${ }^{2}$ Dosen Fakultas Sains dan Teknologi, UIN Walisongo Semarang \\ 1Email Korespondensi: isvana.dalaila99@gmail.com
}

\begin{abstract}
Chrysanthemum including ornamental plant commodities are much-loved community. Chrysanthemum has a high economic value and potential to be developed. The diversity of morphological and anatomical characters is not currently widely practiced. This study aims to determine the morphological and anatomical characteristics of C. morifolium Ramat. var. puspitanusantara, and var. tirtaayuni and C. indicum L. var. mustikakaniya. Sampling by purposive random. The study was conducted in May - June 2017 in Kenteng Village, Bandungan District, Semarang District. The results showed that the results showed that $C$. morifolium Ramat var. puspitanusantara and var. tirtaayuni and C. indicum L. var. mustikakaniya have variations of morphology, especially on leaves and flowers, variations in leaf organ form, and base. Variations of flowering organs include the number of flowers per stem, the number of ribbon flowers, and the freshness of the flower. Anatomical characters based on tissue arrangement of stem and leaf organs have similarities. Keywords: Morphology, Anatomy, ChrysaanthemummorifoliumRamat., Chrysanthemum indicum L.
\end{abstract}

\section{Pendahuluan}

Krisan merupakan tanaman bunga hias berupa perdu, dengan tepi daun bercelah dan bergerigi, serta tersusun berselang-seling pada cabang atau batang. Batang tanaman tumbuh tegak, berstruktur lunak dan berwarna hijau. Jika dibiarkan terus tumbuh, batang ini akan menjadi keras berkayu dan warnanya menjadi hijau kecokelat-cokelatan (Andiani, 2013).

Bunga krisan memiliki banyak jenis, diantaranya krisan jenis C. morifolium Ramat. dan $C$. indicum yang saat ini masih diminati pecinta krisan. Chrysanthemum merupakan tanaman bunga yang tergolong ke dalam famili yang sama dengan bunga aster dan daisy, yaitu famili Asteraceae. C. morifolium Ramat.memiliki banyak varietas, diantaranya ada var. puspita nusantara dan var. tirta ayuni. Varietas ini memiliki bagian yang khusus pada bentuk daun yang bagian tepinya tampak bercelah dan bergerigi (Andiani, 2013).

C. indicum juga memiliki banyak varietas, salah satunya yaitu var.mustika kaniya. Krisan var. mustika kaniya yang paling diminati pecinta krisan yaitu warna ungu dan merah. Varietas ini memiliki bunga dengan mahkota yang lonjong (Purnobasuki, Dewi, dan Wahyuni, 2014). C. morifolium Ramat. dan C. indicum L. merupakan krisan bertipe sprey yaitu krisan yang mempunyai bunga paling sedikit lima kuntum per batang. Ketiga varietas tersebut umum dibudidayakan petani krisan di Bandungan Jawa Tengah. Penelitian tentang tanaman krisan sudah banyak dilakukan, namun pengamatan yang dilakukan belum pada karakter morfologi dan anatomi pada organ batang dan daun. Oleh karena itu penelitian ini dilakukan untuk mengetahui karakter morfologi dan anatomi $C$. morifolium Ramat. var. puspita nusantara, dan var. tirta ayuni serta $C$. indicum L. var. mustika kaniya.

\section{Metode}

Penelitian dilaksanakan pada bulan Mei sampai dengan Juni 2017. Pengambilan sampel dilakukan di Desa Kenteng Kecamatan Bandungan Kabupaten Semarang, dan pengamatan dilakukan di Laboratorium Biologi 
UIN Walisongo Semarang. Alat yang digunakan untuk pengamatan morfologi yaitu gunting kebun, penggaris dan alat tulis, sedangkan untuk pengamatan anatomi alat yang digunakan yaitu mikroskop binokular, optilab, cutter, objek glass dan cover glass. Bahan yang digunakan yaitu batang, daun dan bunga var. puspita nusantara, var. tirta ayuni dan juga var. mustika kaniya. Pengambilan sampel menggunakan purposive random sampling. Sampel C. morifolium Ramat. var. puspita nusantara dan var. tirta ayuni serta C. indicum L var. mustika kaniya yang telah berumur 3 bulan atau waktu panen masingmasing 3 dan diambil foto atau gambar dengan skala penggaris. Pengamatan anatomi sampel dibuat preparat segar yang diletakkan pada kaca benda lalu ditetesi dengan akuades untuk diamati susunan jaringan pada organ batang dan daun.

\section{Hasil dan Pembahasan}

Hasil penelitian menunjukkan bahwa $C$. morifolium Ramat var. puspita nusantara dan var. tirta ayuni serta $C$. indicum L.var. mustika kaniya memiliki variasi morfologi pada organ batang, daun dan bunga, sedangkan karakter anatomi berdasarkan susunan jaringan pada organ batang dan daun memiliki kemiripan. Karakter mofrologi dapat dilihat pada Tabel 1 berikut.

Batang C. morifolium Ramat memiliki panjang batang $95 \mathrm{~cm}$, sedangkan C. morifolium Ramat var. tirta ayuni $76 \mathrm{~cm}$ dan $C$. indicum $\mathrm{L}$. var. mustika kaniya $76 \mathrm{~cm}$, rata-rata panjang batang yaitu $82,3 \mathrm{~cm}$. Batang C. morifolium Ramat dan C. indicum L. tergolong batang basah (herbaceus). Bentuk batang var. puspita nusantara dan var. tirta ayuni serta var. mustika kaniya berahli banyak (angularis) dengan permukaan batang beralur dan berambut. Arah tumbuh batang dan cabang var. puspita nusantara, var. tirta ayuni dan var. mustika kaniya tegak mengarah pada cahaya, dengan jenis percabangan pada batang monopodial serta memiliki tipe cabang sirung pendek.
Tabel 1. Hasil pengamatan karakter morfologi batang C. morifolium Ramat. var. puspita nusantara dan var. tirta ayuni serta $C$. indicum L.var. mustika kaniya

\begin{tabular}{|c|c|c|c|c|}
\hline \multirow[t]{2}{*}{ No } & \multirow{2}{*}{$\begin{array}{l}\text { Karakter } \\
\text { Pengamatan }\end{array}$} & \multicolumn{3}{|c|}{ Tiga Varietas Krisan } \\
\hline & & $\begin{array}{l}\text { var. puspita } \\
\text { nusantara }\end{array}$ & $\begin{array}{l}\text { var. tirta } \\
\text { ayuni }\end{array}$ & $\begin{array}{l}\text { var. } \\
\text { mustika } \\
\text { kaniya }\end{array}$ \\
\hline 1 & Habitus & Herbaceus & Herbaceus & Herbaceus \\
\hline 2 & $\begin{array}{l}\text { Bentuk } \\
\text { batang }\end{array}$ & $\begin{array}{l}\text { Bersegi } \\
\text { banyak } \\
\text { (angularis) }\end{array}$ & $\begin{array}{l}\text { Bersegi } \\
\text { banyak } \\
\text { (angularis) }\end{array}$ & $\begin{array}{l}\text { Bersegi } \\
\text { banyak } \\
\text { (angularis) }\end{array}$ \\
\hline 3 & $\begin{array}{l}\text { Permukaan } \\
\text { batang }\end{array}$ & $\begin{array}{l}\text { Beralur \& } \\
\text { berambut }\end{array}$ & $\begin{array}{l}\text { Beralur \& } \\
\text { berambut }\end{array}$ & $\begin{array}{l}\text { Beralur \& } \\
\text { berambut }\end{array}$ \\
\hline 4 & $\begin{array}{l}\text { Arah } \\
\text { tumbuh } \\
\text { batang }\end{array}$ & Tegak & Tegak & Tegak \\
\hline 5 & $\begin{array}{l}\text { Jenis } \\
\text { percabangan } \\
\text { pada batang }\end{array}$ & Monopodial & Monopodial & Monopodial \\
\hline 6 & Tipe cabang & $\begin{array}{l}\text { Sirung } \\
\text { pendek }\end{array}$ & $\begin{array}{l}\text { Sirung } \\
\text { pendek }\end{array}$ & $\begin{array}{l}\text { Sirung } \\
\text { pendek }\end{array}$ \\
\hline 7 & $\begin{array}{l}\text { Arah } \\
\text { tumbuh } \\
\text { cabang }\end{array}$ & $\begin{array}{l}\text { Tegak } \\
\text { mengikuti } \\
\text { cahaya }\end{array}$ & $\begin{array}{l}\text { Tegak } \\
\text { mengikuti } \\
\text { cahaya }\end{array}$ & $\begin{array}{l}\text { Tegak } \\
\text { mengikuti } \\
\text { cahaya }\end{array}$ \\
\hline 8 & $\begin{array}{l}\text { Warna } \\
\text { batang }\end{array}$ & Hijau muda & Hijau tua & Hijau tua \\
\hline
\end{tabular}

Tabel 2. Hasil pengamatan karakter morfologi daun C. morifolium Ramat. var. puspita nusantara dan var. tirta ayuni serta $C$. indicum L.var. mustika kaniya

\begin{tabular}{|c|c|c|c|c|}
\hline \multirow[t]{2}{*}{ No } & \multirow{2}{*}{$\begin{array}{l}\text { Karakter } \\
\text { Pengamatan }\end{array}$} & \multicolumn{3}{|c|}{ Tiga Varietas Krisan } \\
\hline & & $\begin{array}{l}\text { var. puspita } \\
\text { nusantara }\end{array}$ & $\begin{array}{l}\text { var. tirta } \\
\text { ayuni }\end{array}$ & $\begin{array}{l}\text { var.mustika } \\
\text { kaniya }\end{array}$ \\
\hline 1. & Bentuk daun & $\begin{array}{l}\text { Bulat telur } \\
\text { (ovate) }\end{array}$ & $\begin{array}{l}\text { Jorong } \\
\text { (ovalis) }\end{array}$ & $\begin{array}{l}\text { Bulat telur } \\
\text { (ovate) }\end{array}$ \\
\hline 2. & Ujung daun & $\begin{array}{l}\text { Tumpul } \\
\text { (obtusus) }\end{array}$ & $\begin{array}{l}\text { Tumpul } \\
\text { (obtusus) }\end{array}$ & $\begin{array}{l}\text { Tumpul } \\
\text { (obtusus) }\end{array}$ \\
\hline 3. & Pangkal daun & $\begin{array}{l}\text { Tumpul } \\
\text { (obtuse) }\end{array}$ & $\begin{array}{l}\text { Tidak } \\
\text { simetri atau } \\
\text { miring } \\
\text { (oblique) }\end{array}$ & $\begin{array}{l}\text { Tumpul } \\
\text { (obtuse) }\end{array}$ \\
\hline 4. & $\begin{array}{l}\text { Susunan } \\
\text { tulang daun }\end{array}$ & Menyirip & Menyirip & Menyirip \\
\hline 5. & Tepi daun & $\begin{array}{l}\text { Beringgit } \\
\text { (crenate) }\end{array}$ & $\begin{array}{l}\text { Bergigi } \\
\text { (dentate) }\end{array}$ & $\begin{array}{l}\text { Bergigi } \\
\text { (dentate) }\end{array}$ \\
\hline 6. & Daging daun & Tipis & Tipis & Tipis \\
\hline 7. & Warna daun & $\begin{array}{l}\text { Permukaan } \\
\text { atas hijau } \\
\text { tua dan } \\
\text { bawah hijau } \\
\text { muda }\end{array}$ & $\begin{array}{l}\text { Permukaan } \\
\text { atas hijau } \\
\text { tua dan } \\
\text { bawah hijau } \\
\text { muda }\end{array}$ & $\begin{array}{l}\text { Permukaan } \\
\text { atas hijau } \\
\text { tua dan } \\
\text { bawah } \\
\text { hijau muda }\end{array}$ \\
\hline 8. & $\begin{array}{l}\text { Permukaan } \\
\text { daun }\end{array}$ & $\begin{array}{l}\text { Berambut di } \\
\text { permukaan } \\
\text { atas dan } \\
\text { bawah }\end{array}$ & $\begin{array}{l}\text { Berambut di } \\
\text { permukaan } \\
\text { atas dan } \\
\text { bawah }\end{array}$ & $\begin{array}{l}\text { Berambut } \\
\text { di } \\
\text { permukaan } \\
\text { atas dan } \\
\text { bawah }\end{array}$ \\
\hline
\end{tabular}


Daun C. morifolium Ramatdan C. indicum L.berupa daun tunggal. Struktur daun $C$. morifolium Ramat var. puspita nusantara dan var. tirta ayuni merupakan daun tidak lengkap, hanya memiliki helai daun dan tangkai daun. Susunan tulang daun C. morifolium Ramat var. puspita nusantara dan var. tirta ayuni menyirip (penninervis). Helai daun C. morifolium Ramat var. puspita nusantara dan $C$. indicum $L$. var. mustika kaniya berbentuk bulat telur (ovate) dan var. tirta ayuni berbentuk jorong (ovalis). Ujung daun (apex folii) var. puspita nusantara, var. tirta ayuni dan var. musika kaniya berbentuk tumpul (obtusus). Pangkal daun (basis folii) var. puspita nusantara dan var. mustika kaniya berbentuk tumpul (obtuse) sedangkan var. tirta ayuni berbentuk tidak simetri ati 54 miring (oblique). Tepi daun C. morifolium Ram var. puspita nusantara beringgit (crenate) yakni sinus bersudut runcing dan angulus bersudut tumpul, sedangkan var. tirta ayuni dan var. mustika kaniya bentuk bergigi (dentate) yakni sinus bersudut tumpul dan angulus bersudut runcing (Tjitrosoepomo, 2005).

Tabel 3. Hasil pengamatan karakter morfologi bunga $C$. morifolium Ramat. var. puspita nusantara dan var. tirta ayuni serta $C$. indicum L.var. mustika kaniya

\begin{tabular}{|c|c|c|c|c|}
\hline \multirow[t]{2}{*}{ No } & \multirow{2}{*}{$\begin{array}{l}\text { Karakter } \\
\text { Pengamatan }\end{array}$} & \multicolumn{3}{|c|}{ Tiga Varietas Krisan } \\
\hline & & $\begin{array}{l}\text { var. puspita } \\
\text { nusantara }\end{array}$ & $\begin{array}{l}\text { var. tirta } \\
\text { ayuni }\end{array}$ & $\begin{array}{l}\text { var.mustika } \\
\text { kaniya }\end{array}$ \\
\hline 1 & $\begin{array}{l}\text { Jumlah } \\
\text { bunga per } \\
\text { batang }\end{array}$ & $\begin{array}{l}10-13 \\
\text { kuntum }\end{array}$ & $\begin{array}{l}10-15 \\
\text { kuntum }\end{array}$ & 5- 11 kuntum \\
\hline 2 & $\begin{array}{l}\text { Susunan } \\
\text { bunga } \\
\text { majemuk }\end{array}$ & $\begin{array}{l}\text { Bunga } \\
\text { majemuk tak } \\
\text { berbatas } \\
\text { (bunga } \\
\text { cawan) }\end{array}$ & $\begin{array}{l}\text { Bunga } \\
\text { majemuk tak } \\
\text { berbatas } \\
\text { (bunga } \\
\text { cawan) }\end{array}$ & $\begin{array}{l}\text { Bunga } \\
\text { majemuk tak } \\
\text { berbatas } \\
\text { (bunga cawan) }\end{array}$ \\
\hline 3 & $\begin{array}{l}\text { Lama } \\
\text { kesegaran } \\
\text { bunga } \\
\text { (hari) }\end{array}$ & $\begin{array}{l}12 \text { - } 14 \text { hari } \\
\text { setelah di } \\
\text { potong dan } \\
\text { dalam vas } \\
\text { berisi air } \\
\text { bersih }\end{array}$ & $\begin{array}{l}11 \text { - } 12 \text { hari } \\
\text { setelah di } \\
\text { potong dan } \\
\text { dalam vas } \\
\text { berisi air } \\
\text { bersih }\end{array}$ & $\begin{array}{l}12 \text { - } 14 \text { hari } \\
\text { setelah di } \\
\text { potong dan } \\
\text { dalam vas } \\
\text { berisi air } \\
\text { bersih }\end{array}$ \\
\hline 4 & Tipe bunga & Spray & $\begin{array}{l}\text { Spray/standa } \\
\text { rt }\end{array}$ & Spray/standart \\
\hline 5 & $\begin{array}{l}\text { Warna } \\
\text { bunga pita }\end{array}$ & Kuning & Putih & Ungu muda \\
\hline 6 & $\begin{array}{l}\text { Warna } \\
\text { bunga } \\
\text { tabung }\end{array}$ & $\begin{array}{l}\text { Kuning } \\
\text { kehilauan }\end{array}$ & $\begin{array}{l}\text { Kuning } \\
\text { kehijauan }\end{array}$ & $\begin{array}{l}\text { Kuningan } \\
\text { kehijauan }\end{array}$ \\
\hline 7 & $\begin{array}{l}\text { Bentuk } \\
\text { bunga pita }\end{array}$ & Loniong & Loniong & Loniong \\
\hline 8 & $\begin{array}{l}\text { Lumlah } \\
\text { bunga pita }\end{array}$ & $\begin{array}{l}22-23 \text { per } \\
\text { kuntum }\end{array}$ & $\begin{array}{l}35 \text { per } \\
\text { kuntum }\end{array}$ & $\begin{array}{l}309 \text { per } \\
\text { kuntum }\end{array}$ \\
\hline 9 & $\begin{array}{l}\text { Paniang } \\
\text { bunga pita }\end{array}$ & $2 \pm 3,3 \mathrm{~cm}$ & $1,8 \pm 2,5 \mathrm{~cm}$ & $1,2 \pm 2,6 \mathrm{~cm}$ \\
\hline 10 & $\begin{array}{l}\text { Lebar } \\
\text { bunga pita }\end{array}$ & $0,8 \pm 1,2 \mathrm{~cm}$ & $0,5 \pm 0,9 \mathrm{~cm}$ & $0,2 \pm 1,2 \mathrm{~cm}$ \\
\hline
\end{tabular}

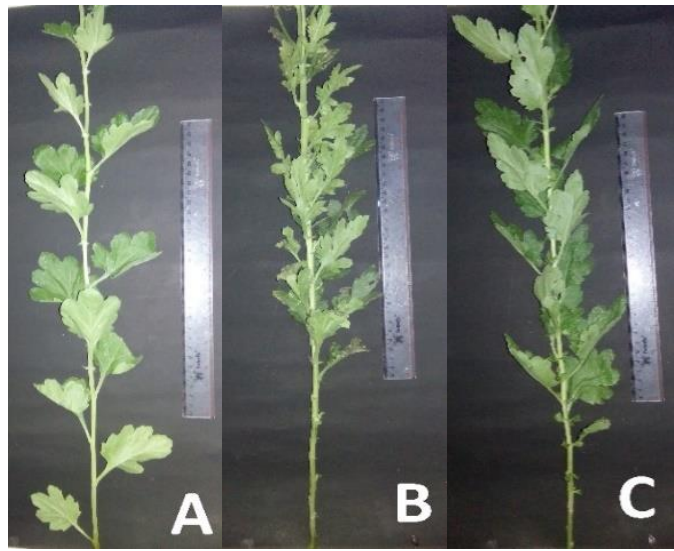

Gambar 1. Morfologi batang C. morifolium Ramat (A) var. puspita nusantara dan (B) var. tirta ayuni serta (C) C. indicum L. var. mustika kaniya

Bunga C. morifolium Ramat var. puspita nusantara dan var. tirta ayuni serta $C$. indicum $\mathrm{L}$. var. mustika kaniya termasuk bunga majemuk tak berbatas (bunga cawan). Bunga cawan terdiri dari bunga pita dan bunga tabung. Bunga tumbuh di ujung batang (flos terminalis) menghadap ke atas. Helaian bunga pita membentang ke luar (straight), bertekstur lunak, berbentuk lonjong, berwarna putih, memiliki tepi yang rata, ujung bunga pita meruncing, pada permukaan bunga pita terdapat guratan yang lebih jelas pada permukaan atas dibandingkan permukaan bawah. Bunga pita memiliki ujung tumpul (Sari, Sukarsa dan Samiyarsih, 2016). Warna bunga pita C. morifolium Ramat var. puspita nusantara kuning, var. tirta ayuni putih dan C. indicum L. var. tirta ayuni ungu muda.

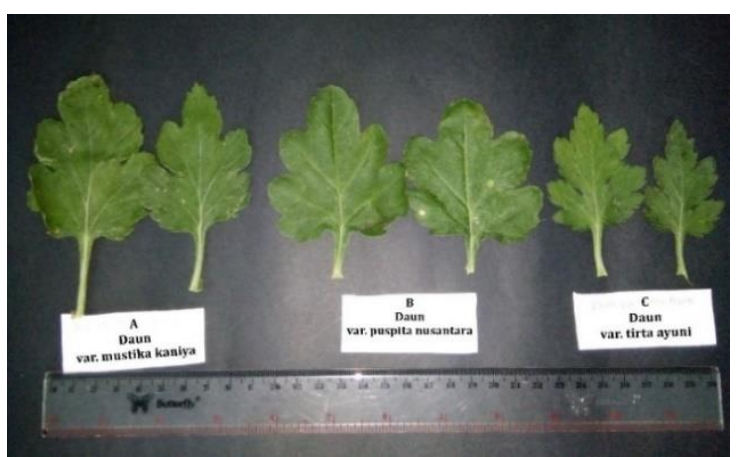

Gambar 2. Morfologi daun (A) C. indicum L.var. mustika kaniya. (B) C. Morifolium Ramat var. puspita nusantara. (C) C. Morifolium Ramat var. tirta ayuni 


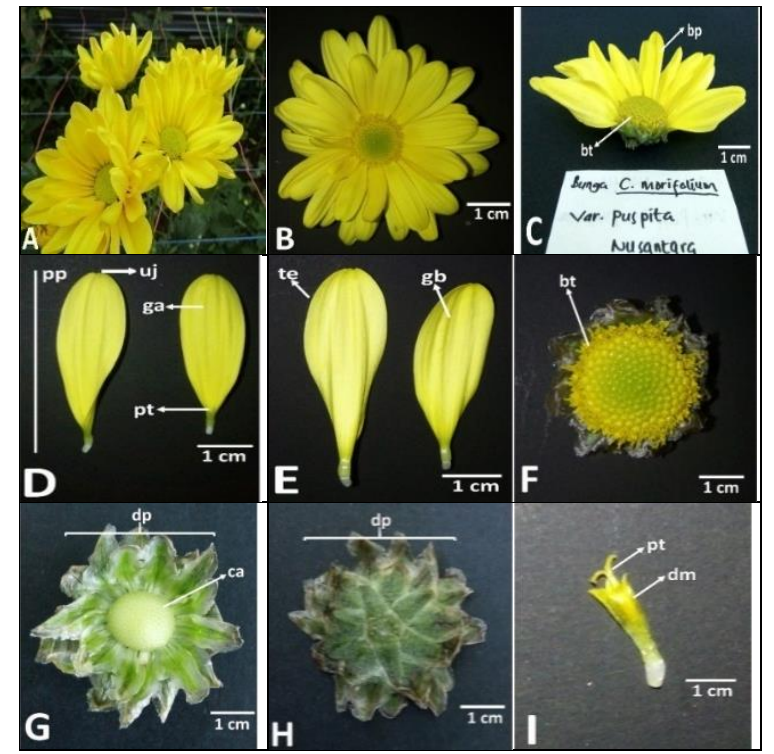

Gambar 3. Bagian-bagian bunga C. morifolium Ramat var. puspita nusantara. (A)bunga pertangkai. (B) bunga. (C) bagian bunga; bp: bunga pita, bt: bunga tabung. (D) permukaan atas bunga pita; pp: panjang bunga pita, pt: putik, ga: guratan atas, uj: ujung bunga pita. (E) permukaan bawah bunga pita; gb: guratan bawah, te: tepi bunga pita yang rata. (F) kumpulan bunga tabung; bt: bunga tabung. (G) daun pembalut dan cakram; dp: daun pembalut, ca: cakram. (H) permukaan bawah daun pembalut; dp: daun pembalut. (I) bunga tabung; pt: putik, dm: daun mahkota.

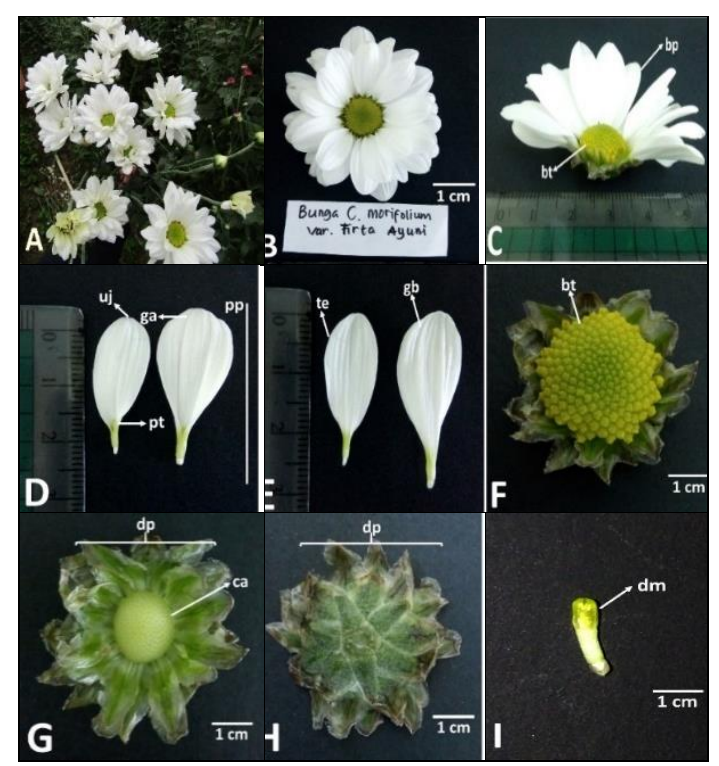

Gambar 4.Bagian-bagian bunga C. morifolium Ramat var. tirta ayuni. (A) bunga pertangkai. (B) bunga. (C) bagian bunga; bp: bunga pita, bt: bunga tabung. (D) permukaan atas bunga pita; pp: panjang bunga pita, pt: putik, ga: guratan atas, uj: ujung bunga pita. (E) permukaan bawah bunga pita; gb: guratan bawah, te: tepi bunga pita yang rata. (F) kumpulan bunga tabung; bt: bunga tabung. (G) daun pembalut dan cakram; $\mathrm{dp}$ : daun pembalut, ca: cakram. (H) permukaan bawah daun pembalut; dp: daun pembalut. (I) bunga tabung; dm: daun mahkota.

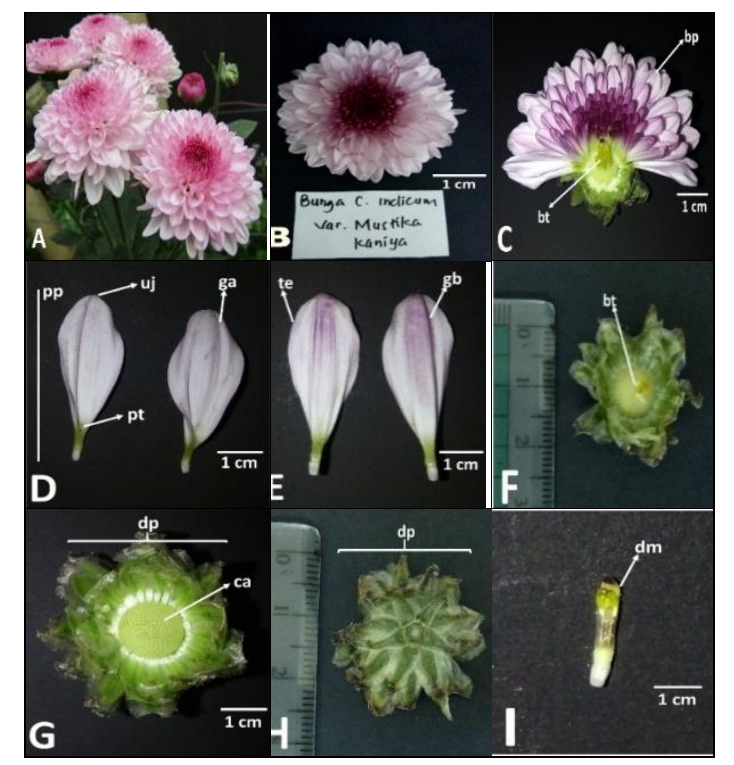

Gambar 5.Bagian-bagian bunga $C$. indicum var. mustika kaniya. (A) bunga pertangkai. (B) bunga. (C) bagian bunga; bp: bunga pita, bt: bunga tabung. (D) permukaan atas bunga pita; pp: panjang bunga pita, pt: putik, ga: guratan atas, uj: ujung bunga pita. (E) permukaan bawah bunga pita; gb: guratan bawah, te: tepi bunga pita yang rata. (F) kumpulan bunga tabung; bt: bunga tabung. (G) daun pembalut dan cakram; dp: daun pembalut, ca: cakram. (H) permukaan bawah daun pembalut; dp: daun pembalut. (I) bunga tabung; dm: daun mahkota.

Jumlah bunga pita $C$. morifolium Ramat var. puspita nusantara 23 helai, panjang $2 \pm 3,3$ $\mathrm{cm}$ dan lebar 0,8 $\pm 1,2 \mathrm{~cm}, C$. morifolium Ramat var. tirta ayuni jumlah bunga pita 35 helai, panjang 1,8 $\pm 2,5 \mathrm{~cm}$ dan lebar $0,5 \pm 0,9 \mathrm{~cm}$, dan C. indicum L var. mustika kaniya 309 helai, panjang 1,2 $\pm 2,6 \mathrm{~cm}$ dan lebar 0,2 $\pm 1,2 \mathrm{~cm}$. Setiap helaian bunga pita terdapat putik. Bunga tabung pada $C$. morifolium Ramat var. puspita nusantara dan var. tirta ayuni lebih banyak dan tersusun padat dan menggerombol di tengah serta jelas terlihat tanpa membuang bunga pita dibandingkan $C$. indicum L. var. mustika kaniya yang lebih sedikit dan akan terlihat jika dibuang 
bagian bunga pita. Bunga $C$. morifolium Ramat. terdapat persamaan pada tepi bunga pita yang rata, warna daun pembalut yang hijau, warna bunga tabung kuning kehijauan dan putik yang bercabang menjadi dua dan berwarna kuning (Purnobasuki, Dewi, dan Wahyuni, 2014).

Tabel 4. Hasil pengamatan organ batang (a) dan daun (b)

\begin{tabular}{|c|c|c|}
\hline No & Varietas & Hasil Pengamatan \\
\hline 1 & $\begin{array}{l}\text { puspita } \\
\text { nusanta- } \\
\text { ra }\end{array}$ & atmats \\
\hline
\end{tabular}

(a)

Keterangan gambar:

(1) Trikomata non glandular; (2) Epidermis; (3) Korteks; (4) Floem; (5) Kambium tidak mengalami penebalan sekunder; (6) Xilem; (7) Empulur

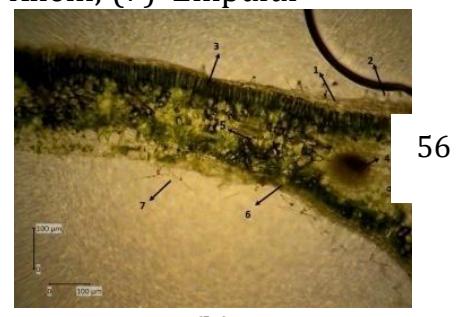

(b)

Keterangan gambar:

(1) Epidermis atas; (2) Trikoma non glandular atas; (3) Parenkim palisade; (4) Berkas pengangkut; (5) Parenkim spons; (6) Epidermis bawah; (7) Trikoma non glandular bawah

tirta

ayuni

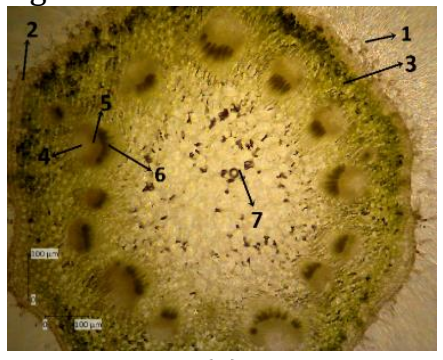

(a)
Keterangan gambar:

(1) Trikomata non glandular; (2)

Epidermis; (3) Korteks; (4)

Floem; (5) Kambium tidak mengalami penebalan sekunder; (6) Xilem; (7) Empulur

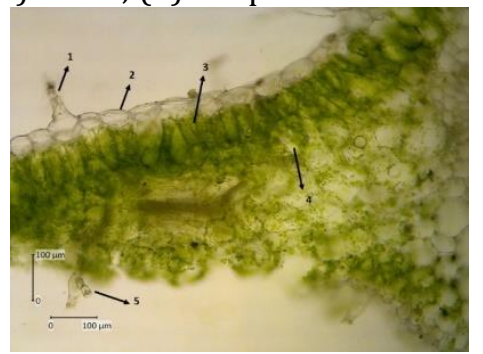

(b)

Keterangan gambar:

(1) Trikoma non glandular atas;

(2) Epidermis atas; (3) Parenkim palisade; (4) Parenkim spons; (5) Trikoma non glandular bawah
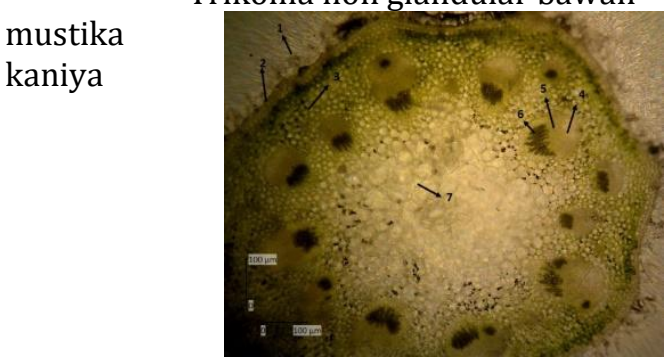

(a)

Keterangan gambar:

(1) Trikomata non glandular; (2) Epidermis; (3) Korteks; (4) Floem; (5) Kambium tidak mengalami penebalan sekunder; (6) Xilem; (7) Empulur

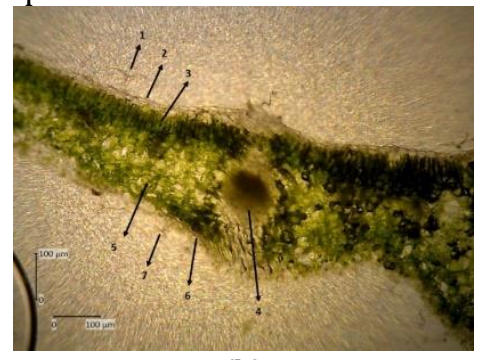

(b)

Keterangan gambar:

(1) Trikomata non glandular atas;

(2) Epidermis atas; (3) Parenkim palisade; (4) Berkas pengangkut; (5) Parenkim spons; (6) Epidermis bawah; (7) Trikomata non glandular bawah 
Jaringan penyusun batang C. morifolium Ramat. var. puspita nusantara dan var. tirta ayuni serta $C$. indicum $\mathrm{L}$. var. mustika kaniya dari luar ke dalam yaitu trikomata non glandular, epidermis, korteks, floem, kambium tidak menebal, xilem dan empulur. Epidermis terdiri dari satu lapis sel tunggal, dan berbentuk pipih. Sel epidermis terdapat modifikasi membentuk derivat berupa trikomata. Trikomata merupakan rambut bersel satu atau bersel banyak dibentuk dari sel epidermis (Armanda, 2015). Trikomata pada var. puspita nusantara dan var. tirta ayuni yaitu trikoma non glandular bertipe trikoma multisel yang bercabang. Korteks terdiri dari parenkim yang berbentuk bulat, berdinding tipis, dan bervakuola besar. Fungsi utama korteks yaitu penyimpan cadangan makanan (Mulyani, 2006). Tipe berkas pengangkut pada var. puspita nusantara, var. tirta ayuni dan var. mustika kaniya yaitu kolateral terbuka, yaitu diantara xilem dan floem terdapat kambium yang tidak mengalami penebalan sekunder (Mulyani, 2006).

\section{Simpulan}

Hasil pengamatan menunjukkan bahwa $C$. morifolium Ramat. var. puspita nusantara dan var. tirta ayuni serta $C$. indicum $\mathrm{L}$. var. mustika kaniya terdapat variasi karakter morfologi pada organ batang, daun dan bunga. Variasi morfologi pada batang meliputi warna batang, dan ukuran batang, sedangkan pada daun meliputi bentuk daun, pangkal daun, dan tepi daun, serta pada bunga meliputi jumlah bunga per batang, lama kesegaran bunga (hari), warna bunga pita, jumlah bunga pita, panjang bunga pita dan lebar bunga pita. Karakter anatomi C. morifolium Ramat. Var. puspita nusantara dan var. tirta ayuni serta $C$. indicum L. var. mustika kaniya berdasarkan susunan jaringan pada organ batang dan daun memiliki kemiripan.

\section{Daftar Pustaka}

Andiani, Yuli. 2013. Budidaya Bunga Krisan. Yogyakarta: Pustaka Baru Press.

Armanda, Dian Triastari. 2015. AnatomiTumbuhanBerbasis Unity of Sciences. Semarang: CV. KaryaAbadi Jaya.

Mulyani, Sri. 2006. Anatomi Tumbuan. Yogyakarta: Kanisius.

Nugroho, Hartanto., Purnomo, Isserep Sumardi. 2006. Struktur Perkembangan Tumbuhan. Jakarta: Penebar Swadaya.

Purnobasuki, Hery, Anika Sindhya Dewi, \& Dwi Kusuma Wahyuni. 2014. Variasi Morfologi Bunga Pada Beberapa Varietas Chrysanthemum morifolium Ramat. J. Natural B. 2 (3): 210-220.

Sari, Indah Anugrah., Sukarsa.,\&SitiSamiyarsih. 2016. AnalisisFenetikKultvarKrisan (Chrysanthemum morifoliumRamat.). J. Biosfera. Vol. 33 (2): 52-59.

Tjitrosupomo, Gembong. 2005. Morfologi Tumbuhan. Yogyakarta: UGM Press. 